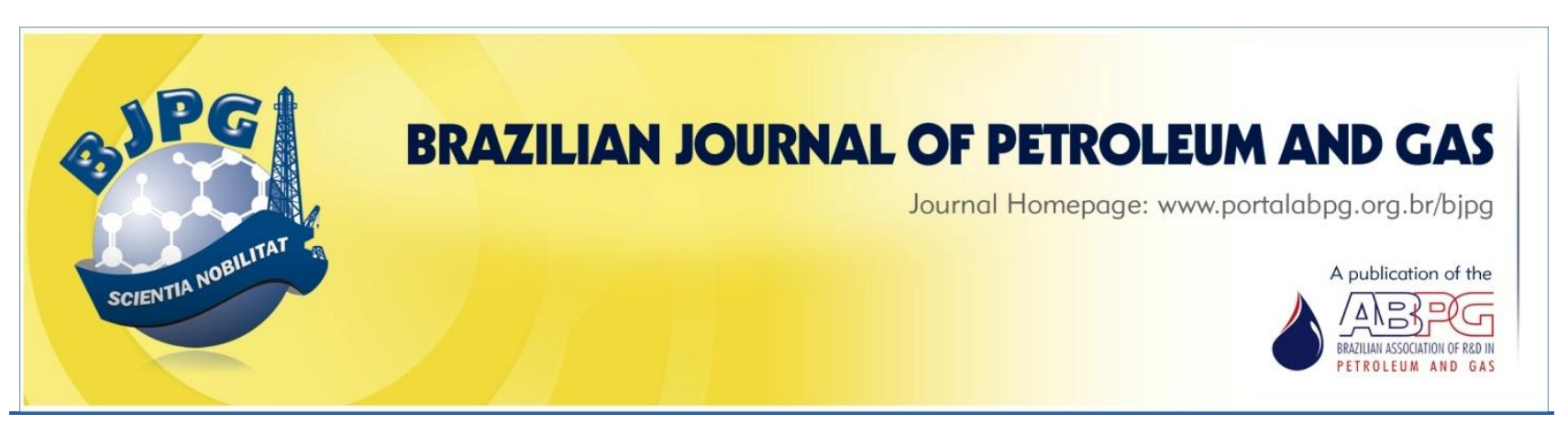

\title{
MICROEMULSION-BASED FLUSHING FLUID FOR EFFECTIVE REMOVAL OF FILTER CAKE IN WELLS CEMENTATION
}

\footnotetext{
${ }^{\text {a }}$ Curbelo, F. D. S. ${ }^{1} ;{ }^{a}$ Caminha, T. T.; ${ }^{a}$ Garnica, A. I. C.; ${ }^{a}$ Melo, G. N. A.; ${ }^{a}$ Araújo, E. A.; ${ }^{b}$ Freitas, J. C. O.

${ }^{a}$ Federal University of Paraiba, Department of Chemical Engineering, João Pessoa - PB - Brazil

${ }^{b}$ Federal University of Rio Grande do Norte, Chemical Institute, Natal - RN - Brazil
}

Received: 07.01.2019 / Revised: 15.05.2019 / Accepted: 19.06.2019 / Published on line: 08.10.2019

\section{ABSTRACT}

The objective of this work is to evaluate the effective removal of mud cake formed by drilling fluid for microemulsion-based flushing fluid. The microemulsions were prepared with vegetable castor oil, $2 \% \mathrm{wt}$ $\mathrm{KCl}$ as aqueous phase, and nonionic surfactant (Ultranex NP40). Thermal stability, rheological, removal, and wettability inversion were performed to evaluate the performance of the microemulsion-based flushing fluid. Rheological tests showed that microemulsions behaved like Newtonian fluids. The best formulation of flushing fluid was $70 \%$ surfactant $/ 25 \%$ oil phase $/ 5 \%$ aqueous phase, with cloudy temperature at $365.25 \mathrm{~K}$, removal efficiency of mud cake of $84.85 \%$, and high capability of wettability inversion.

\section{KEYWORDS}

nonionic surfactant; microemulsion; flushing fluid; mud cake; well cementing

\footnotetext{
${ }^{1}$ To whom all correspondence should be addressed.

Address: Federal University of Paraiba, Department of Chemical Engineering, João Pessoa, PB, Brazil. ZIP Code: 58051-900 | Phone number: +55 83 99613-8786 | e-mail: fabioladias@yahoo.com doi:10.5419/bjpg2019-0012
} 


\section{INTRODUCTION}

Oil well drilling is carried out through the drill bit that traverses geological formations looking for hydrocarbons. The rock fragments are removed by the injection of a drilling fluid through the space formed between the column and the wall of the well (annulus) (Agarwal et al., 2013). During the process, the direct contact of the fluid with the rock formation produces a low permeability film called mud cake (Ba geri et al., 2017).

After the drilling operation is completed, the space between the well and the casing tube is cemented. The drilling fluid and mud cake must be removed completely to achieve a safe cementation operation. Complementary fluids, called flushing fluids, have primordial role in this case, being injected to assist in the cleaning of the well wall, and to invert the wettability (Quintero et al., 2007; Quintero et al., 2015; Wang et al., 2016).

The flushing fluid should be carefully developed to avoid interaction with the drilling fluids and the cement, allowing the efficient removal of the mud cake formed and recovering the water-wet condition to improve the adhesion of the cement to both formation and coating. Ideally, flushing fluids should exhibit Newtonian fluid behavior for the variation of the temperature along the well. To achieve this goal, more efficient and economically viable flushing fluids are needed (Brandl et al., 2013).

Microemulsions are composed of two immiscible liquids and a surfactant (nonionic). In some cases, when the surfactant is ionic, a cosurfactant needs to be used to reduce electrostatic repulsion. The surfactant assists in promoting the solubilization of these immiscible liquids, making their molecules more stable inside the micelles than in their original phase. Thus, one immiscible liquid can be spontaneously dispersed in the other liquid, making the microemulsion a thermodynamically stable system (Winsor, 1968).

This work proposes the development of environmentally-friendly microemulsions, formulated with biodegradable vegetable oil (castor oil), biodegradable nonionic surfactant (Ultranex NP40), and $\mathrm{KCl} 2 \% \mathrm{wt}$ aqueous phase. These microemulsions are to be used as potential flushing fluids to remove the mud cake formed by the drilling fluid for safe cementation operation. This process evaluates its thermal stability, rheological behavior, removal efficiency of mud cake, and its capability to obtain wettability inversion.

\section{MATERIALS AND METHODS}

\subsection{Ternary phase diagram}

Ternary phase diagram was developed to determine the microemulsion region by Winsor classification (Winsor, 1968). To build the ternary diagram, a mixture of two constituents (mass fraction) was used and titrated with the third one to observe possible phase changes. In a ternary phase diagram, the compositions may be represented by triangular coordinates, being important to determine the zones of solubility of the blend, using the specific proportions of the components.

For the construction of the phase diagram, the masses of the aqueous and oily phases were measured, according to the chosen calculation basis. Then, the nonionic surfactant was added until the emulsion zone disappeared and the microemulsion formed (one phase). The mixture was stirred with help of the vortex for maximum homogenization and, when necessary, centrifuged.

A flushing fluid consists basically of oil and water and may contain surfactants. In the cementing operation, only the flushing fluid shows Newtonian behavior. All other fluids, such as drilling fluids and cement, exhibit non-Newtonian behavior, that is, their viscosities vary according to the shear rate (Wang et al., 2016).

The flushing fluid (microemulsion) was formulated basically of vegetable oil (castor oil), aqueous phase $(2 \% \mathrm{KCl}$ weight), and nonionic surfactant (Ultranex NP 40 by Oxiteno, Brazil). In a suitable beaker, the components were mixed in the chosen fractions within the microemulsion region, obtaining the flushing fluid.

Ultranex NP 40, the nonionic surfactant, was obtained by reaction of nonylphenol with ethylene oxide (4 EO) liquid at $298.15 \mathrm{~K}, \mathrm{pH}$ between 5.5 and 7.0, cloudy point of $309.15 \mathrm{~K}-319.15 \mathrm{~K}$ (Technical 
Bulletin by Oxiteno). Castor oil, which is extracted from seeds of Ricinus communis, differs from other vegetable oils in that it is rich in a unique carboxylate, ricinoleate (Ayuba et al., 2017). Ninety percent of the total triacylglycerols are triricinoleates (Schneider et al., 2004; Schneider et al., 2013). It has high viscosity and its hydrophilicity may be advantageous for the formation of a microemulsion W/O (Grace et al., 2017) and it is biodegradable (Kunduru et al., 2015). The ricinoleate moiety makes castor oil more polar than other vegetable oils (Shombe et al., 2016; Salimon et al., 2011).

\subsection{Thermal stability}

The microemulsion was placed in a suitable vessel under heating (temperature control) and was stirred constantly (with a magnetic stirrer), at a rate of about $1 \mathrm{~K} / 60 \mathrm{~s}$. The temperature of the system was visually monitored and quantified when the system was totally cloudy. The thermal stability test aimed to evaluate the performance of the flushing fluid in the drilling process due to the temperature gradient along the oil wells.

\subsection{Rheology test}

For the rheological study of the flushing fluid, tests were performed using the Brookfield LV DVIII Ultra Rheometer with CPE52 spindle. The rheometer was linked to a thermostatic bath and to a computer which enables the viscosity of the microemulsions to be measured in the range of $303.15 \mathrm{~K}$ to $333.15 \mathrm{~K}$, varying every $10 \mathrm{~K}$, with accuracy of $1 \mathrm{~K}$, providing viscosity values, shear stress, and shear rate. The measurements were made automatically at each temperature, varying only the speed of rotation, in the rotation range of 1 to $90 \mathrm{rpm}$.

\subsection{Removal test}

This test simulated the removal of the drilling fluid from the borehole's wall using a microemulsion-based flushing fluid. Initially, we prepared $2.5 \times 10^{-4} \mathrm{~m}^{3}$ of the microemulsion, heated it under agitation up to $361.15 \mathrm{~K}$. Simultaneously, the non-aqueous drilling fluid was homogenized with a Hamilton-Beach agitator for 1800 seconds. After agitating, about $0.04 \times 10^{-4} \mathrm{~m}^{3}$ of the drilling fluid was poured into a beaker to completely cover the visualizing frame (Figure 1) to form a uniform filter cake film. Subsequently, the

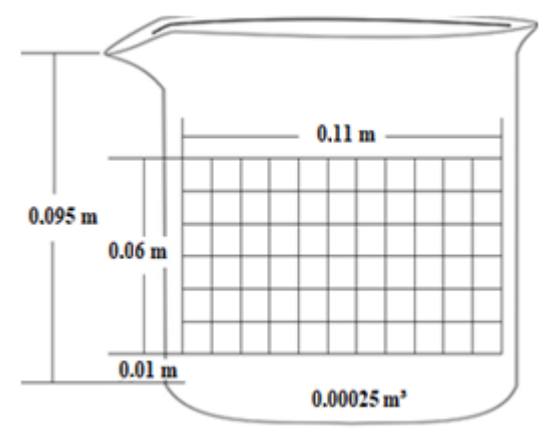

Figure 1. Schematic representation of the visualizing frame.

microemulsion was carefully poured into the beaker in the opposite side of the visualizing frame to maintain it intact. This procedure was done in accordance to API RP 10B-2 (API, 2013) standards.

The beaker was placed on the Fann 35 viscometer and, simultaneously, the chronometer was started. The removal test lasted a maximum time of 600 seconds, being the chronometer stopped before the end time when the visualizing frame was completely clean (Campos, 2014). Finally, the percentage of clean area in relation to the total area of the visualizing frame was calculated, obtaining, therefore, the efficiency of the cleanup fluid, according to the equations 1 and 2 , namely, the cleaning efficiency of the flushing fluid.

Removed area $=$ (number of squares removed) $\mathrm{x} 0.0001 \mathrm{~m}^{2}$

Removal efficiency $=($ removed area $/ 0.0066$ $\left.\mathrm{m}^{2}\right) \times 100 \%$

\subsection{Wettability inversion test}

Synthetic oil-based drilling fluids can be altered by the continuous addition of water-based fluids containing surfactants (flushing fluids) under dynamic conditions. The magnitude of these changes can be observed by using specific techniques, such as microscopy or electrical conductivity measurements (Quintero et al., 2015). The brine-in-oil (W/O) microemulsion has nearzero conductivity, whereas oil-in-brine (O/W) microemulsion has high conductivity, like the aqueous phase.

Phase inversion may occur gradually or suddenly with change of composition depending 


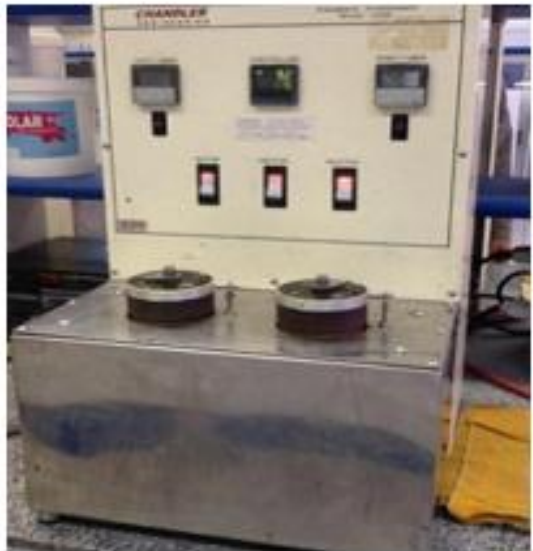

(a)

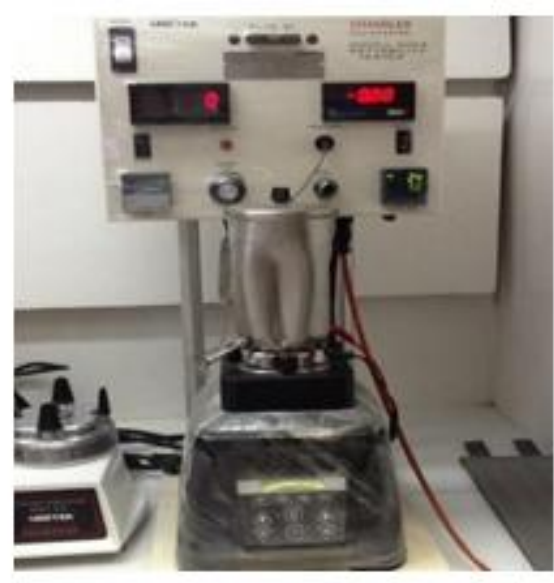

(b)

Figure 2. (a) Atmospheric consistometer, (b) Wettability test facility.

on the correct formulation of the surfactant mixture used in flushing fluids. At the phase inversion point, the fluid system undergoes its lowest interfacial tension. Under these conditions, spontaneous microemulsification occurs between the oil and water phases of the system.

In preparation for the wettability inversion test, oil-based drilling fluids were initially placed at an atmospheric consistometer Chandler Model 1200 (Figure 2a) to be warmed up to the testing temperature at $361.15 \mathrm{~K}$. Afterwards, they were carried to the wettability tester Chandler Model 3065 (Figure 2b), where the phase inversion point was measured by electrical conductivity. This procedure was done in according API RP 10B-2, (2013) standards.

\section{RESULTS AND DISCUSSION}

\subsection{Analysis of the behavior of the nonionic surfactant}

Figure 3 depicts the ternary phase diagram for the aqueous solution $2 \% \mathrm{KCl}(\mathrm{AP}) /$ vegetable oil (OV)/nonionic surfactant (S).

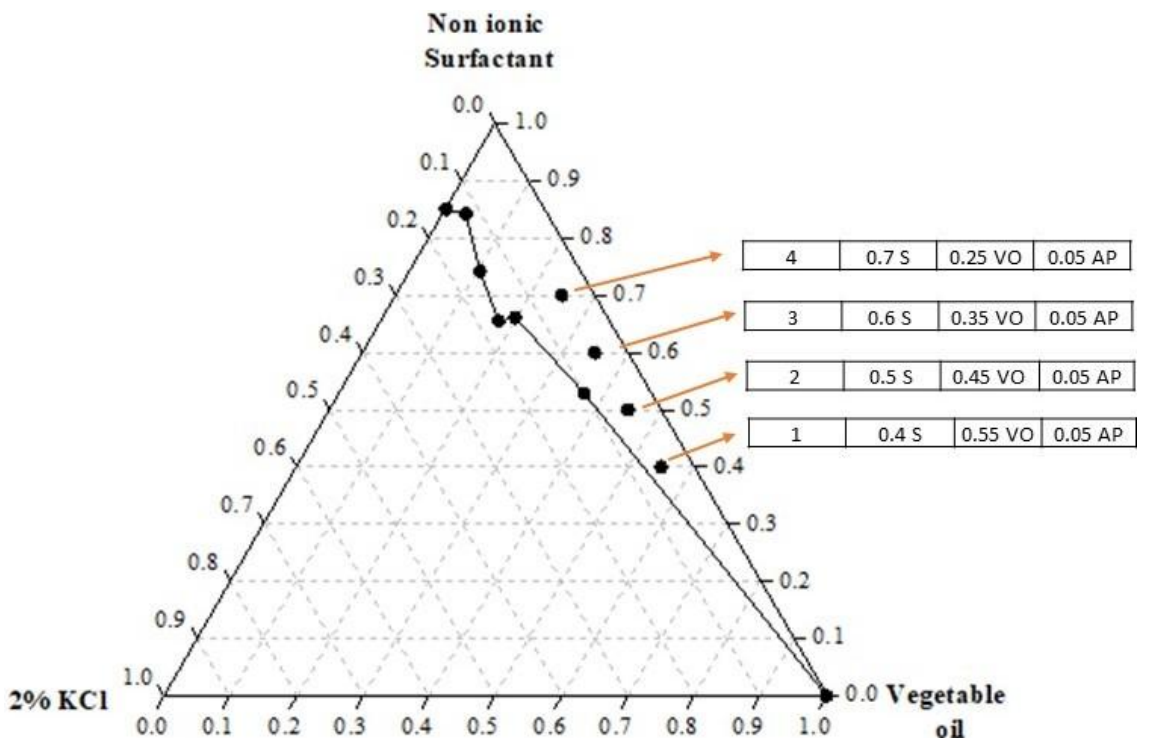

Figure 3. Ternary diagram: $2 \% \mathrm{KCl}(\mathrm{AP})$, vegetable oil (VO) and nonionic surfactant (S). 
Table 1. Turbidity temperature of microemulsion systems.

\begin{tabular}{ccc}
\hline Flushing fluid & Weight fraction (\%) (S/VO) & Turbidity temperature \\
\hline $\mathbf{1}$ & $0.40 / 0.55$ & $329.95 \mathrm{~K} \pm 0.5 \mathrm{~K}$ \\
$\mathbf{2}$ & $0.50 / 0.45$ & $337.85 \mathrm{~K} \pm 0.5 \mathrm{~K}$ \\
$\mathbf{3}$ & $0.60 / 0.35$ & $354.55 \mathrm{~K} \pm 0.5 \mathrm{~K}$ \\
$\mathbf{4}$ & $0.70 / 0.25$ & $365.25 \mathrm{~K} \pm 0.5 \mathrm{~K}$ \\
\hline
\end{tabular}

In Figure 3, microemulsion regions (Winsor IV) were identified in the diagram, which was the interesting region to continue the tests. Four points were chosen within the microemulsion region to perform the subsequent tests.

\subsection{Thermal stability test}

Initially, the thermal stability tests were evaluated by the turbidity temperature of the system. The thermal stability of the microemulsions is shown in Table 1. All experiments were done in duplicate and did not present a considerable variation in the obtained values.

According to the results shown in Table 1 , the turbidity temperature of the microemulsion systems studied increases as the amount of oil decreases. As the temperature of microemulsion system increases, there is a higher affinity of the oil for nonionic surfactant (Hydrophilic Lipophilic Balance - HLB 8.9) and lower affinity of the water to nonionic surfactant, so microemulsion systems 3 and 4 (Table 1) have enough oil and surfactant to maintain stability of W/O microemulsions at higher temperatures. Thus, as they the oil content increases in comparison to surfactant, the temperature decreases, because the surfactant solubilization in the oil is not favored and the ability to stabilize the water in the microemulsion decreases.

According to the thermal stability test (Table 1), knowing that average temperature of the oil wells is around $328.15 \mathrm{~K} \pm 0.5 \mathrm{~K}$, in this scenario (in Brazil), all the four microemulsion systems evaluated presented good results, but the

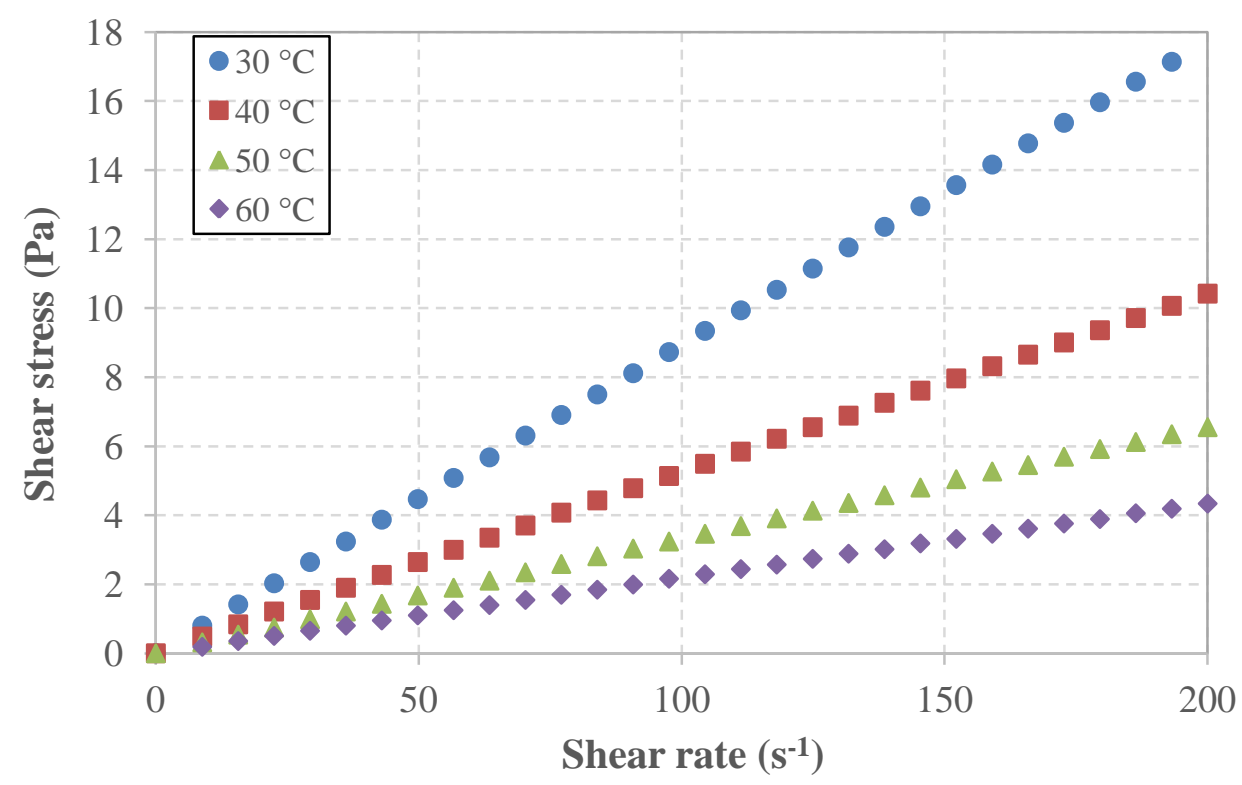

Figure 4. Rheological results for flushing fluid 3. 


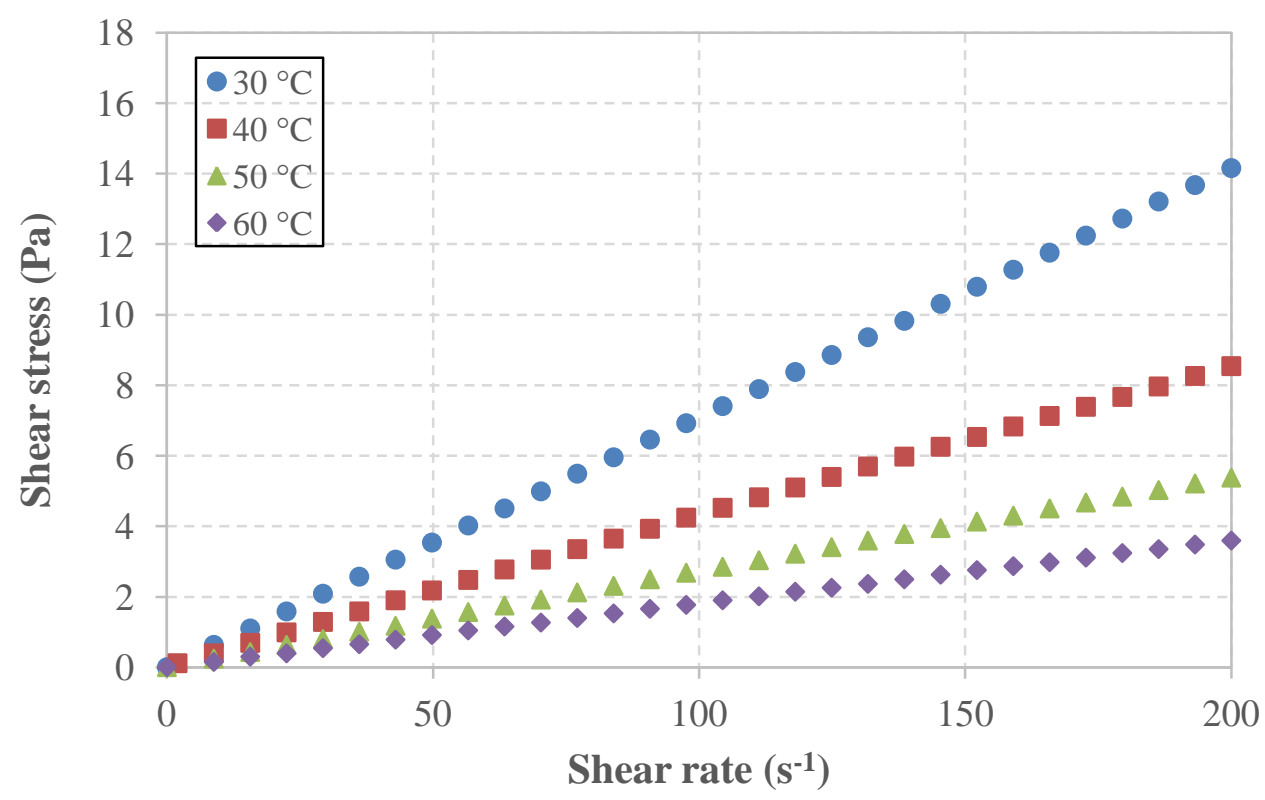

Figure 5. Rheological results for flushing fluid 4.

microemulsion systems 3 and 4 obtained the best results, $354.55 \mathrm{~K} \pm 0.5 \mathrm{~K}$ and $365.15 \mathrm{~K} \pm 0.5 \mathrm{~K}$, respectively. Based on these results, flushing fluids 3 and 4 were selected for rheological, removal, and wettability inversion tests.

\subsection{Rheology test}

The rheological tests were performed for microemulsion systems 3 and 4 . The behavior of the shear stress in relation to shear rate is shown in Figures 4 and 5.

From rheological tests (Figures 4 and 5), it was possible to observe that the microemulsion systems analyzed presented a shear stress directly proportional to the shear rate, at all the temperatures (303.15 K to $333.15 \mathrm{~K})$, being characterized as Newtonian fluids.

Newtonian fluids are most suitable for use as flushing fluid because the viscosity remains constant, and this feature is desired for the best removal of the mud cake (Ba geri et al., 2017; Wang et al., 2016), due to temperature and pressure variations that may occur in oil well. In addition, the experimental results showed a higher viscosity for microemulsion 3 , which corresponds to the greater proportion of oil phase (castor oil), when compared to the other microemulsion system analyzed (Grace et al., 2017).

\subsection{Removal test}

Removal tests verify the efficiency of the flushing fluid formulated, by looking at the removal time of a film of the drilling fluid. The removal test was performed for flushing fluids 3 and 4 (Figure 6). All the experiments were done in duplicate and did not present a considerable variation in the obtained values.

Figure 6a shows the thin layer of drilling mud, which must be removed by microemulsion-based flushing fluids. The removal of this layer (clean area) by flushing fluid 3 is shown in Figure $6 \mathrm{~b}$ and by flushing fluid 4 in Figure 6c. By equations 1 and 2 , the percentage of removal was calculated indicating $75.75 \pm 0.2 \%$ and $84.85 \pm 0.2 \%$ of removal efficiency for flushing fluids 3 and 4 , respectively. These results were obtained for test time of 510 and 540 seconds for flushing fluids 3 and 4, respectively. The best result was observed for flushing fluid 4 , because the nonionic surfactant has a low HLB (8.9), being hydrophobic, removing more as surfactant amount increases in the microemulsion.

\subsection{Wettability inversion test}

The wettability inversion test of a flushing fluid is obtained by analyzing the variation of electrical conductivity. The test takes place by titrating the 


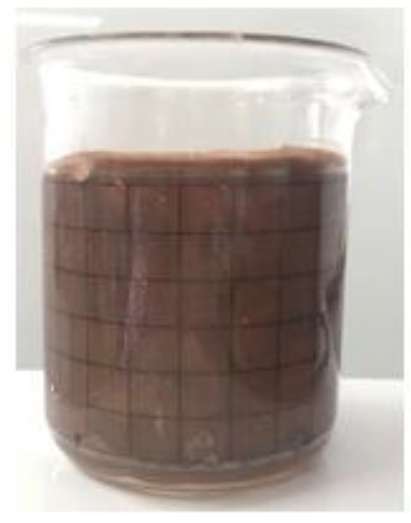

(a)

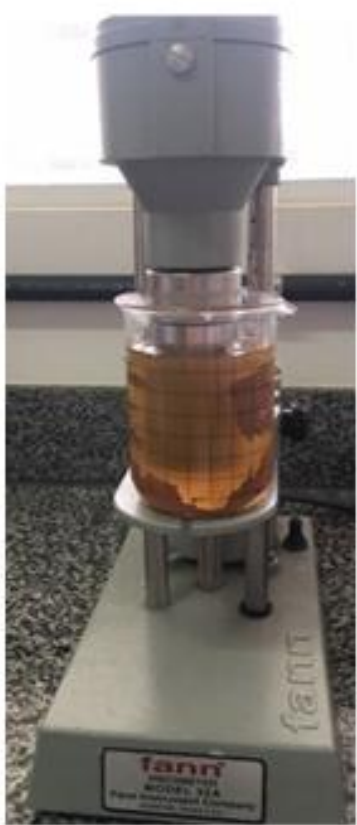

(b)

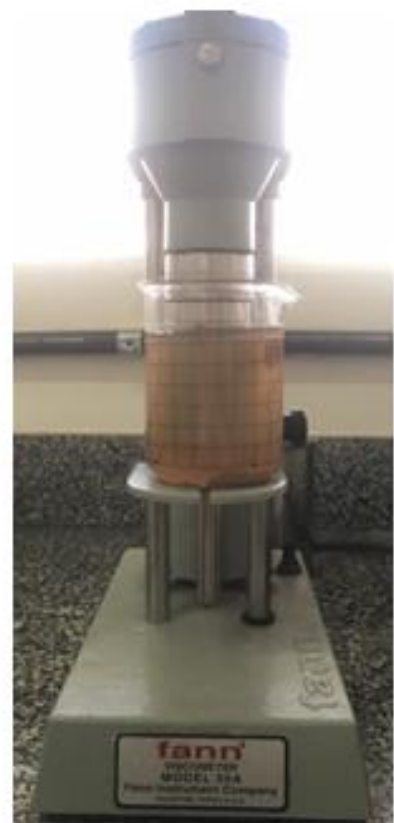

(c)

Figure 6. Removal test for flushing fluids: thin layer of drilling mud (a), removal by flushing fluids 3 (b) and 4 (c).

microemulsion in the drilling mud. As the fluid inverts the wettability from the continuous oil phase to the aqueous phase, the device measures the electrical activity and exhibits the results as the apparent wettability. The titration only stops when the electrical conductivity reaches a stable value greater than 1 (Christian et al., 2009).

The apparent wettability was obtained from the microemulsion to drilling fluid volume ratio used in the test. The results obtained were:

- Flushing fluid 3 diluted: for 1:1 and 1:10 ratio, the total inversion was reached after adding $0.18 \times 10^{-4} \mathrm{~m}^{3}$ and $0.23 \times 10^{-4} \mathrm{~m}^{3}$ of microemulsion, respectively, in $2.0 \times 10^{-4} \mathrm{~m}^{3}$ of drilling fluid, thus, resulting in an apparent wettability ranged of $9 \%$ to $11.5 \%$;

- Flushing fluid 4 diluted: for 1:1 and 1:10 ratio, the total inversion was reached after adding $0.16 \times 10^{-4} \mathrm{~m}^{3}$ and $0.21 \times 10^{-4} \mathrm{~m}^{3}$ of microemulsion, respectively, presenting apparent wettability that ranged from $8 \%$ to $10.5 \%$.

\section{CONCLUSIONS}

In this work, we developed formulations of microemulsions composed of vegetable oil and non-ionic surfactant to verify their potential as flushing fluid for future application in the oil industry through thermal, rheological stability, and removal tests.

Based on the results presented above, it is possible to conclude that the formulation with the greatest potential to act as flushing fluid was flushing fluid 4 , because it had a cloudy temperature (365.25 K $\pm 0.5 \mathrm{~K})$ which was above the average temperature of the wells $(328.15 \mathrm{~K} \pm$ $0.5 \mathrm{~K})$, showing a high resistance of the microemulsion at high temperatures. It presented the Newtonian fluid behavior, thus, it was possible to predict the rheological behavior along the well. From removal test, flushing fluid 4 also obtained better results compared to flushing fluid 3 , with percentages of clean area of $84.85 \pm 0.2 \%$ and $75.75 \pm 0.2 \%$, respectively. However, both obtained high wettability inversion capacity.

Nevertheless, the microemulsified system formulated presented the characteristics required to act as a flushing fluid in cementation operations, being ecologically friendly (biodegradable). 


\section{ACKNOWLEDGMENTS}

The authors thank the Institutional Program for Scientific Initiation (CNPq - PIBIC/UFPB) and Foundation for Research Support of Paraiba (FAPESQ/PB) for the scholarships granted, the Laboratory of Cement at Federal University of Rio Grande do Norte, and Oxiteno, Brazil for the technical support.

\section{REFERENCES}

Agarwal, S.; Phuoc, T. X.; Soong, Y.; Martello, D.; Gupta, R. K. Nanoparticle-stabilized invert emulsion drilling fluids for deep-hole drilling of oil and gas. The Canadian Journal of Chemical Engineering, v. 91, p.1641-1649, 2013.

https://doi.org/10.1002/cjce.21768

API - American Petroleum Institute. Recommended Practice for Testing Well Cements, API RP 10B-2, 2013.

Ayuba, L.; Agboire, S.; Gana, A. K.; Ishaq, M.; Aliyu, U.; Affiniki, G.; Manjang, J. I. Efficacy of castor oil in the control of throat, skin and enteric bacteria. Advances in Food Science and Engineering, v. 1(3), p. 95-99, 2017. https://doi.org/10.22606/afse.2017.13001

Ba geri, B.S.; Mahmoud, M.; Abdulraheem, A.; Al-Mutairi, S. H.; Elkatatny, S. M.; Shawabkeh, R. A. Single stage filter cake removal of barite weighted water based drilling fluid. Journal of Petroleum Science and Engineering, v. 149, p. 476-484, 2017. https://doi.org/10.1016/i.petrol.2016.10.059

Brandl, A.; Acorda, E.; Ellis, T.; Bray, W. Improving mud removal and simplifying challenging cement design: a deepwater case history in the South China sea. In: International Petroleum Technology Conference, 2013, Beijing, China. https://doi.org/10.2523/IPTC-16761-MS

Campos, G. PROCELAB - Procedimentos e métodos de laboratório destinados à cimentação de poços de Petróleo (Procedures and methods laboratory for cementing of oil wells). M12, p. 1-3, 2014.
Christian, C. F.; Ellis, D. R.; Brege, J. J.; Quintero, L.; Clark, D. E. The development of an effective water-wetting cement spacer for the displacement of non-aqueous fluids (NAF). In: AADE National Technical Conference and Exhibition Held, New Orleans, p. 1 - 5, 2009.

Grace, S. A.; Sutton, A. M.; Abraham, N.; Armbrecht, E. S. Presence of mast cells and mast cell degranulation in scalp biopsies of telogen effluvium. International Journal of Trichology, v. 9, p. 25-29, 2017. https://doi.org/10.4103/ijt.ijt 4316

Kunduru, K. R.; Basu, A.; Haim Zada, M.; Domb, A. J. Castor Oil-Based Biodegradable Polyesters. Biomacromolecules. 2015, v. 16, p. 2572-2587. https://doi.org/10.1021/acs.biomac.5b00923

Quintero, L.; Jones, T. A.; Clark, D. E. NAF filtercake removal using microemulsion technology. In: The European Formation Damage Conference, SPE 107499, Netherlands, 2007.

https://doi.org/10.2118/107499-MS

Quintero, L.; Passanha, W. D.; Aubry, E.; Poitrenaud, $\mathrm{H}$. Advanced microemulsion cleaner fluid applications in deep water wells. In: Offshore Technology Conference, Rio de Janeiro, 2015. https://doi.org/10.4043/26344-MS

Salimon, J.; Nallathamby, N.; Salih, N.; Abdullah, B. M. Synthesis and physical properties of estolide ester using saturated fatty acid and ricinoleic acid. Journal of Automated Methods and Management in Chemistry, v. 2011, p. 1-4, 2011.

https://doi.org/10.1155/2011/263624

Schneider, R. C. S.; Baldissarelli, V. Z.; Trombetta, F.; Martinelli, M.; Caramão, E. B. Optimization of gas chromatographic-mass spectrometric analysis for fatty acids in hydrogenated castor oil obtained by catalytic transfer hydrogenation. Analytica Chimica Acta, v. 505, p. 223-226, 2004. https://doi.org/10.1016/i.aca.2003.10.070

Schneider, R. C. S.; Lara, L. R. S.; Ceolin, M. M.; Kaercher, J. A.; Schneider, M. Environmental impact of castor oil catalytic transfer hydrogenation. Clean Technologies and Environmental Policy, v. 15, p. 977-985, 2013. https://doi.org/10.1007/s10098-012-0567-1 
Shombe, G. B.; Mubofu, E. B.; Mlowe, S.; Revaprasadu, N. Synthesis and characterization of castor oil and ricinoleic acid capped CdS nanoparticles using single source precursors. Materials Science in Semiconductor Processing, v. 43, p. 230-237, 2016.

https://doi.org/10.1016/i.mssp.2015.11.011

Wang, C.; Meng, R.; Xiao, F.; Wang, R. Use of nanoemulsion for effective removal of both oilbased drilling fluid and filter cake. Journal of Natural Gas Science and Engineering, v. 36, p. 328338, 2016. https://doi.org/10.1016/i.jngse.2016.10.035
Winsor, P. A. Binary and multicomponent solutions of amphiphilic compounds. Chemical Reviews, v. 68, p. 1-40, 1968. https://doi.org/10.1021/cr60251a001 